\title{
ENHANCING WRITING ABILITY OF STUDENTS THROUGH MULTIPLE DRAFTS AND CRITICAL COMMENTS
}

\author{
Purna Bahadur Kadel*
}

\begin{abstract}
This is an exploratory study through which the researcher conducted the research based on survey research design to find out the existing practices of providing feedbacks and perceptions of faculties in developing writing through multiple drafts and critical comments at B.Ed. level. Fifty respondents were selected from constituent and affiliated colleges as informants adopting purposive non-random sampling procedure to collect data. Questionnaire and informal interview were administered as tools to elicit the data for this study. It was found that the practice of brainstorming, planning, writing multiple drafts, revising and editing can enhance writing skills. The writing of multiple drafts facilitates the students to use mechanics and orthography adequately and develop cohesive and coherent writing. Moreover, it was found that students need teachers' written as well as oral comments and feedbacks in developing writing skills; teachers' critical written feedback and comments are more effective than oral feedback and most of the learners rarely keep on writing multiple drafts in the most of the colleges at the Tribhuvan University.

Key Words: Multiple drafts, critical comments, Feedbacks, orthography, revising, editing, and brainstorming.

\section{INTRODUCTION}

Learning to write well is a difficult and challenging task for preservice teachers since they need to require more efforts in grammar, contents and vocabulary to develop writing skills. In order to have mastery over the writing skills, they need to have overwhelming competence in fundamental process of writing skills, such as collecting information through brainstorming, planning, writing, revising, editing etc. The writing skills are essential for the tertiary level students to carry out assignment, term papers, and formal examination successfully. Moreover, they have to write resume, memos, memoirs, applications, mini-theses, reports etc. Teaching writing helps the students become effective learners through learning to think, and learning to learn writing skills. With writing skills, the learners can develop cognitive growth, critical and creative thinking skills.
\end{abstract}

Dr. Kadel is Lecturer in English Education at Central Department of Education, Tribhuvan University, Kirtipur, Kathmandu, Nepal. 
Most of the students in tertiary level are from government-aided higher secondary schools who are used to learning through lower order thinking skills, such as memorization, rote learning and by-hearting techniques. They have lack of accuracy and fluency of writing due to depending on conventional mode of teaching and learning writing like product wring approach. The teachers adopt the traditional product writing approach despite the fact that process, genre-based and integrated writing approaches have been introduced over past two decades. Teachers are concerned with the final product writing approach and not much attention is paid to process and genre-based writing approaches. The students are asked to write on a particular topic with a stipulated word limit without paying attention on collecting information, planning out the essays, revising, and editing. The writing of the students is very unsatisfactory and full of erroneous due to various causes, such as lack of adequate training to the faculties and students, late starting of teaching writing skills, mismatch between writing theory and practice, inadequate language materials and input of teachers.

The trends of teaching writing skills have been shifted from product writing approach to process writing approach over the last two decades. However, product and process writing approaches cannot be separated to develop the writing skills. The writer should know the purposes of his/her writing and who would be the reader of his/her writing so the level of writing should match according to the proficiency level of readers otherwise the writing cannot be effective. The large number of students depends on the product writing approach without paying attention of the prewriting, collection of information, brainstorming, planning, writing, revising, rewriting, editing etc. before producing a final draft. The skills of rearranging, reshaping, revising, rewriting, and reediting are the essential procedures to produce a final creative and critical writing. All of the writers need to learn what their readers expect and whether their writing is understood by their readers.

Writing is a social act. When the students talk, they want someone to listen to them. In the similar vein, when students write, they want someone to read what they have written. Feedback whether written or oral remains an important component of ESL/EFL classroom situation in academic writing. Teachers' comments/feedbacks are very necessary to avoid grammatical, vocabulary and content errors of learners to enhance writing. To avoid grammatical, mechanical and vocabulary errors, relevant feedbacks from the teachers on time is inevitable.

Writing is an essential skill among the four skills, viz. listening, speaking, and reading since it is a means of assessing the ability of learners in every walk of life. Moreover, writing is a main mode of giving and taking 
examination of university, schools, public commission services, and university commission services in the world including Nepal. Writing skill can be developed after developing the listening, speaking, and reading skills. It is developed in the latter part of learners. Learners need conscious level of mind to learn writing skills. They need to develop the cognitive, physical, and psychomotor aspects to develop writing skills. They depend on only product writing approach to develop writing. They have to be provided with critical comments time and again by the tutors in order to develop their writing skills. Moreover, writing skills cannot be developed overnight miraculously. The students of B.Ed. are very poor in writing skills though they are competent in grammar, vocabulary and content knowledge. Their scores in the compulsory and optional English are very low in final examination. They have problems with accuracy and fluency of writing skills.

The focus of writing until 1970s was on the features of L2 written text, orthography, sentence-level structure, and discourse level structures. There was paradigm shifting of L2 writing from textual features to the process writing in the late 1970s and 1980s. The notion of writing as process was introduced by Zamel (1970). The process-based approach emphasizes on the notion of writing as a process of developing organization as well as meaning. The writing process is regarded as a nonlinear, exploratory and generative process. Writers discover and formulate their ideas while rewriting and trying to approximate meaning in revision (Zamel, 1983). Writing can be developed through writing multiple drafts, adding, deleting, modifying and rearranging the ideas and editing final draft by correcting vocabulary, sentence structure, grammar and mechanics. Process writing is regarded as a complex, recursive and creative set of writing behavior. Learning to write through writing incorporates developing an efficient and effective writing process. The writer is engaged in discovery and expression of meaning through multiple drafts and formative feedbacks by the teachers.

In process writing, writing is considered as creative thinking, but not as linguistic competence. Competence in writing process is more important than linguistic competence in the ability to write proficiently in English (Zamel, 1982). The basic writing skills can be acquired to develop higher order of writing skills which can be enhanced through multiple drafts and teacher comments. The primary role of a language teacher is to provide both error corrections and provide negative and positive feedbacks. The trends of providing feedbacks can be traced back from behavior learning theory. In the cognitive view of learning, the function of feedback is not only to provide reinforcement, but also provides information which helps the learners use actively in modifying their behaviors (Zamel, 1981). According to Chaudron (1988), the information which is available through feedbacks allows the 
learners to confirm or disconfirm and possible modification of the hypothetical transitional rules of their grammars.

Over the last 20 years, there have been changes in writing pedagogy. In education, feedback is widely used as a crucial tool for both encouraging and consolidating learning (Anderson, 1982; Brophy, 1981; as cited in Hyland and Hyland, 2006). The existing practices of types of feedback and comments while producing multiple drafts by the learners are: oral feedback, written feedback, peer feedback, teacher feedback, writing workshops, conferences and computer delivered feedback. Summative feedback was replaced by formative feedback which aims at improving students' writing ability through writing multiple drafts processes. The teacher provides the feedbacks and critical comments during the courses continuingly in formative evaluation system; however, in summative evaluation, feedbacks and comments are delivered to learners at the end of the course.

Teacher's feedback on students' writing is a critical and nonnegotiable aspect of writing instruction. Teacher's feedback provides tailored instruction according to the needs of individual students through face to face dialogue in teacher students writing conference. Teacher should provide feedback at various stages of writing process not just at the end and not just grammar; but the teacher should provide the feedback in every aspect of writing of the students. Oral feedback is provided during conversational interaction which helps the learners facilitate the L2 writing acquisition. Long's interactional hypothesis (Long, 1983) proposes the second language learning that is facilitated through interactional processes due to the role of interaction in connecting input internal learner capabilities particularly selective attention and output in productive ways. The teacher follows various techniques to provide feedback to the students such as peer response groups, teacher and students' conferences, audio-taped commentary reformulation and computer-based commentary; however, hand written commentary on students' drafts is the primary method of response (Ferris, 1997).

Written feedback has of paramount importance when the focus is on improving the students' composition writing skills. Many researchers have noted that comments on preliminary drafts are more useful in revising the scripts than commenting on final drafts (Krashen, 1984; Freedman, 1987). Students can forget the oral comments and may not remember it for a long time whereas the students can reread and remember the written feedbacks at any time and place (Fathman and Whalley, 1990). In second language context, effectiveness of feedback on error correction is regarded positively. 


\section{OBJECTIVES OF THE STUDY}

The objectives of this study were as follows:

- $\quad$ To identify the existing practices of teaching writing skills at tertiary level of Tribhuvan University

- $\quad$ To be acquainted with the perceptions of faculties in developing writing skills of pre-service teachers through multiple drafts and critical comments

- $\quad$ To suggest the pedagogical implication of this study

\section{RESEARCH QUESTIONS}

(a) What are the existing practices of teaching writing skills at tertiary level at Tribhuvan University?

(b) What are the perceptions of the faculties in developing writing skills of pre-service teachers through multiple drafts and critical comments?

\section{SIGNIFICANCE OF THE STUDY}

This study would be a milestone for teaching writing skills to ESL/EFL learners. Particularly, the policy makers, syllabus designers, teachers, students, and researchers will be benefited with this study since this study will provide them blueprint regarding the teaching writing skills to the tertiary level students. More importantly, the concerned stakeholders will be familiar with the role of feedbacks and multiple drafts to develop writing skills.

\section{METHODS}

This is an exploratory study through which the researcher carried out the research to find out the existing practices of providing feedbacks and perceptions of faculties in developing writing through multiple drafts in tertiary level. This was a survey research in which researcher followed the steps of survey research design to carry out the study.

All of the English teachers teaching at constituent and affiliated colleges were the population of this study. Fifty English teachers teaching in B.Ed. in affiliated and constituent colleges of Tribhuvan University were the sample population of this study. Questionnaire and informal interview were the tools of data collection. Questionnaire was administered to the respondents and finally, informal interview to the subject teachers was conducted to collect data.

\section{RESULTS OF THE STUDY}

It was found that the practice of planning prior to writing helped the learners to organize the ideas coherently; majority of them (80\%) responded that the writing of multiple drafts on the same topic helped the learners write accurately; $84 \%$ of the teachers claimed that the practices of writing multiple 
drafts helped the students develop their flow of writing; and most of the them claimed that writing multiple drafts sensitized the students to use punctuation mark, spelling and capitalization adequately. It was revealed that those strategies of writing multiple drafts made them become competent in developing cohesive and coherent writing in tertiary level; $44 \%$ (22) of them claimed that most of the faculties at constituent and affiliated colleges of the Tribhuvan University never made the students write multiple drafts as strategies to develop writing skills at tertiary level.

It was found that the students should be given ample opportunities to have practices of strategies of fundamental features of writing; the students can enhance writing skills through proper brainstorming, planning, writing multiple drafts and editing; collaborative writing tasks also help the students develop their writing skills. The majority of respondents agreed that students needed teachers' written as well as oral comments as feedbacks in developing writing skills; teachers' critical written feedback and comments are more effective than oral feedback; and most of the learners rarely keep on writing multiple drafts in the most of the colleges at the Tribhuvan University.

\section{DISCUSSION}

Seventy percentage (35) of the respondents stated that the practices of planning prior to writing helped the learners organize the ideas coherently. Likewise, $80 \%$ (40) of them stated that the writing of multiple drafts on the same topic helped the learners write accurately. However, only $20 \%$ (10) of them argued that multiple drafts on the same topic did not help the students write accurately. Approximately, 84\% (42) of the teachers claimed that the practices of writing multiple drafts helped the students develop their flow of writing. Moreover, most of the respondents stated that writing multiple drafts sensitized the students to use punctuation marks, spelling and capitalization adequately. A majority (56\%) of faculties argued that strategies of writing multiple drafts made them smart in developing cohesive and coherent writing in tertiary level. Likewise, $44 \%$ (22) of the respondents claimed that most of the faculties at constituent and affiliated colleges of the Tribhuvan University never made the students write multiple drafts as strategies to develop writing skills at tertiary level.

Approximately, $60 \%$ (30) of the respondents stated that the students had to be given ample opportunities to have practices of strategies of fundamental features of writing, such as topic sentence, organization of ideas, brainstorming, supporting sentences, main argument, coherence and cohesion in the classroom to enhance writing. Majority of respondents (54\%) stated that the students can enhance writing skills through proper brainstorming, planning, writing multiple drafts and editing. In the similar vein, 58\% (29) of the respondents asserted that collaborative writing tasks also helped the students develop their writing skills. Sixty two percent (31) of them argued 
that syllabus of B.Ed. does not prescribe assignment and term paper in developing writing skills in four year curriculum of B.Ed. as internal assessment in the curriculum. Despite the fact that the academic writing is prescribed in second year of four year B.Ed., practices of writing multiple drafts has not been prescribed in the syllabus of tertiary level. Majority of the respondents claimed that writing skills of B.Ed. students need to be developed to carry out the term papers, assignments, and formal examinations academically.

Majority of respondents (58\%) stated that students needed teachers' written as well as oral comments as feedbacks in developing writing skills, such as organization of ideas, coherent and cohesive paragraph writing and developing paragraphing with adequate topic sentence and supportive topic sentences. Most of the respondents stated agreed that teachers' critical written feedback and comments play more effective role than oral feedbacks since the faculties could provide clear cut errors by circling and underlining with red marks on the erroneous places where the learners commits errors, in addition to this, the teachers supply the cues, hints as well as answers on the wrongful answers of writing of the students. Majority of the respondents asserted that in fact, there is no culture of writing multiple drafts while carrying out assignments and term papers at constituent colleges of Tribhuvan University. However, there is a culture of giving feedbacks in writing in private colleges. More importantly, writing culture must be initiated among the students of tertiary level in order to develop their academic writing skills. It was found that most of the learners rarely keep on writing multiple drafts in the most of the colleges at the Tribhuvan University.

\section{CONCLUSION}

It is concluded that there is no culture of writing multiple drafts of compulsory subjects as well as optional English in B.Ed. level in most of constituent colleges of Tribhuvan University. However, in affiliated public colleges, the culture of multiple drafts in course of carrying out assignments and culture of providing oral feedbacks are still in practices in established public colleges so the results of English of those colleges are better than the constituent and private colleges at TU. Feedbacks and comments are the main backbone of developing writing skills. It was concluded that writing cannot be academically sound without being followed the strategies of process writing, such as brainstorming, planning, revising, and editing until publishing a final draft.

\section{WORKS CITED}

Chaudron, C. (1984). "The effect of feedback on students' composition revision." RELC journal. Vol. 15(2), 1-14.

--- (1988). Second language classroom: Research on teaching and learning. Cambridge: Cambridge University Press. 
Fathman, A.K. \& Whalley, E. (1990). "Coaching from margins: issues in written response." In B. Kroll (ed.). Second language writing: Research insights for the classroom. Cambridge: Cambridge University Press.

Ferris, D.R. (1997). "The influence of teacher commentary on student revision." TESOL Quarterly. Vol. 31(2), 315-339.

Freedman, S.W. (ed.) (1987). The acquisition of written language response and revision. Norwood. NJ: Ablex.

Hyland, F. \& Hyland, K. (2001). "Sugaring the pill, praise, and criticism in written feedback." Journal of Second Language Writing. Vol. $10,185-212$.

Hyland, K. \& Hyland, F. (2006). Feedback in second language writing: Contexts and Issues. Cambridge: Cambridge University Press.

Krashen, S.D. (1984). Writing: Research theory and application. Oxford: Pergamon Institute of English.

Long, M.H. (1983). "Native speaker/Non-native speaker conversation and negotiation of comprehensive input." Applied linguistics. Vol. 4(2), 121-141.

Zamel, V. (1982). "Writing: the process of discovering meaning?" TESOL Quarterly. Vol. 16(2), 195-209.

--- (1983). "The composing process of advanced ESL students: six case studies." TESOL Quarterly. Vol. 17(2), 165-187.

--- (1985). "Responding to student writing." TESOL Quarterly. Vol. 19(1), 79-101. 